\title{
Ocular injuries from improvised explosive devices
}

\begin{abstract}
Purpose To document the characteristics, treatments, and anatomical and functional outcomes of patients with ocular trauma from improvised explosive devices (IEDs).

Methods Retrospective review of ocular injuries caused by IEDs, admitted to our tertiary referral centre.
\end{abstract}

Results In total, sixty-one eyes of the 39 patients with an average age of 24 years (range, 20-42 years) were included in the study. In total, $49(80 \%)$ eyes of the patients had open-globe and $12(20 \%)$ had closed-globe injury. In eyes with open-globe injury, intraocular foreign body (IOFB) injury was the most frequently encountered type of injury, observed in $76 \%$ of eyes. Evisceration or enucleation was required as a primary surgical intervention in $17(28 \%)$ of the eyes. Twentytwo $(36 \%)$ eyes had no light perception at presentation. Patients were followed up for an average of 6 months (range, 4-34 months). At the last follow-up, 26 (43\%) of 61 eyes had no light perception. Postoperative proliferative vitreoretinopathy (PVR) developed in 12 (50\%) of the 24 eyes that underwent vitreoretinal surgery, and four of these eyes became phthisical. There were no cases of endophthalmitis. The presence of open-globe injury and presenting visual acuity worse than $5 / 200$ were significantly associated with poor visual outcome $(<5 / 200, P<0.05)$. In eyes with open-globe injury, the presence of an IOFB was not associated with poor visual outcome $(P>0.05)$.

Conclusion Ocular injuries from IEDs are highly associated with severe ocular damage requiring extensive surgical repair or evisceration/enucleation. Postoperative PVR is a common cause of poor anatomical and visual outcome.

Eye (2011) 25, 1491-1498; doi:10.1038/eye.2011.212; published online 19 August 2011

Keywords: improvised explosive devices; ocular trauma; vitreoretinal surgery
FC Erdurman, V Hurmeric, G Gokce, AH Durukan, $\mathrm{G}$ Sobaci and HI Altinsoy

\section{Introduction}

Ocular injuries caused by explosive materials are strongly associated with severe ocular morbidity and visual impairment. ${ }^{1-5}$ Improvised explosive devices (IEDs), also known as roadside bombs, have been used increasingly in recent years. The term 'IEDs' has also become commonly used to describe homemade explosives, especially following the Iraq conflict in 2003. ${ }^{3}$ IEDs are highly destructive explosives and mostly include additional materials such as rocks, metal, or glass fragments to increase the lethal effects of shrapnel propelled by the explosion. Especially in terrorist acts and in conditions of irregular warfare, IEDs are the most commonly used explosive devices, producing devastating ocular and ocular adnexal injuries. ${ }^{3}$

In this study, we aimed to document the characteristics, treatments, and outcomes of patients with ocular trauma caused by IEDs.

\section{Materials and methods}

This study was performed under an institutional ethics review board-approved protocol. We conducted a retrospective chart review of all patients admitted to the Department of Ophthalmology at the Gulhane Military Medical Academy (Ankara, Turkey) with diagnoses of ocular trauma caused by IEDs from January 2006 through December 2008. All of the casualties injured in terrorist attacks underwent an initial evaluation by ophthalmologists at the regional military hospitals. Urgent surgical interventions including primary open-globe repair or evisceration/enucleation were performed either at these regional hospitals or at our department. After urgent medical and/or surgical interventions following the injury, all patients were transferred by an air ambulance. Patients with only ocular adnexal damage or minor ocular injuries such as corneal abrasions or corneal/conjunctival foreign bodies were not included in the study. Casualties who died
Department of

Ophthalmology, Gulhane Military Medical Academy and School of Medicine, Ankara, Turkey

Correspondence: FC Erdurman, Department of Ophthalmology, Gulhane Military Medical Academy and School of Medicine, Etlik 06018, Ankara, Turkey Tel: + 9031230458 69; Fax : + 903123045850 .

E-mail: erdurman@ yahoo.com

Received: 22 March 2011 Accepted in revised form: 16 June 2011

Published online: 19 August 2011

This study was presented at the 44th National Congress of Turkish Ophthalmology Society, 29 September3 October 2010, Antalya, Turkey. 
before completion of surgical management for ocular injury were also not included. Concomitant non-ocular injuries such as brain, maxillofacial, thoracic, and orthopaedic injuries were recorded.

In patients transferred after primary surgical intervention, data including initial ocular status and details of primary surgery were collected from the medical records of the regional military hospitals. All patients underwent orbital computed tomography scan at the regional hospitals. In patients with stable ocular and systemic status, ophthalmic examination was combined with B-mode ultrasonography, and ultrasound biomicroscopy; other patients were evaluated in the operating room under general anaesthesia, especially in cases with completely destroyed eyes.

Antibiotic prophylaxis was administered in all patients with open-globe injury before referral to our tertiary care centre. In addition, systemic corticosteroid therapy was also given if there was no contraindication.

Ocular injuries were classified according to the criteria described by the Ocular Trauma Classification Group (OTCG), including: type of injury, visual acuity at initial examination, presence or absence of a relative afferent pupillary defect (RAPD), and zone of injury. ${ }^{6}$ The initial and final Snellen visual acuities were categorised using the OTCG grading system. Grade 1 was better than $20 / 40$. Grade 2 was from 20/50 to 20/100. Grade 3 was from $19 / 100$ to $5 / 200$. Grade 4 was from $4 / 200$ to light perception. Grade 5 was no light perception. Data included patient age, gender, involved eye, initial ocular findings, concomitant non-ocular injuries, surgical details and complications, follow-up time, and anatomical and visual outcomes. Final visual outcome was defined as poor if visual acuity was $<5 / 200$.

The pars plana vitrectomy (PPV) procedure was performed using standard 20-gauge three-port pars plana technique. A non-contact fundus observation system (EIBOS; Möller-Wedel GmbH, Wedel, Germany) was used for wide-angle viewing. In the presence of lens damage, PPV was combined with pars plana lensectomy. In eyes with perforating globe injury or with a foreign body penetrated into the choroid, chorioretinectomy was also performed for posterior segment reconstruction. The Eckardt style temporary keratoprosthesis (Heinrich Wöhlk Kontaktlinsen, Kiel, Germany) was used in cases with severe corneal injury obscuring the operative view. Silicone oil (1000/5000 centistokes (cs) or heavy silicone oil) was used for internal tamponade. The choice of silicone oil was determined by the surgeon's preferences and depending on the patient's retinal conditions.

Statistical analysis was performed using SPSS 10.0 for Windows (SPSS, Chicago, IL, USA). The $\chi^{2}$ - and Fisher's exact tests were used for analysing intergroup differences in distribution. McNemar's tests were used to analyse before $v$ s after comparisons. Statistical significance was set at $P<0.05$.

\section{Results}

Sixty-one eyes of the 39 patients with ocular injuries from IEDs were included in the study. Thirty-one (79\%) of the patients injured by IEDs were either drivers or passengers in vehicles; the other $8(21 \%)$ patients were injured while conducting a foot patrol in the area. All patients, except one, were male with a mean age of 24 years (range, 20-42 years). Forty-nine (80\%) eyes of the patients suffered open-globe injury; 12 (20\%) experienced closed-globe injury. The right eye was involved in eight $(21 \%)$ cases; the left eye was involved in nine (23\%) cases; there was bilateral involvement in $22(56 \%)$ of the patients. Although 7 (12\%) of the 61 eyes did not require any surgical intervention, the remaining 54 (88\%) eyes required surgery: repair of corneoscleral lacerations in 31 (51\%), evisceration/enucleation in $17(28 \%)$, globe exploration in $3(5 \%)$, and PPV in $3(5 \%)$. All of the seven eyes that did not require any surgical intervention had closed-globe injuries. Mean follow-up was 6 months (range, 4-34 months). Patients' demographic characteristics and primary surgical interventions are listed in Table 1.

Table 1 Demographic features of the patients and primary surgical interventions

\begin{tabular}{|c|c|}
\hline Number of the patients (eyes) & $39(61)$ \\
\hline Gender (male/female) & $38 / 1$ \\
\hline Mean age (range) in years & $24(20-42)$ \\
\hline \multicolumn{2}{|l|}{ Eye involved } \\
\hline Right, $n(\%)$ & $8(21)$ \\
\hline Left, $n(\%)$ & $9(23)$ \\
\hline Both, $n(\%)$ & $22(56)$ \\
\hline \multicolumn{2}{|l|}{ Types of injuries } \\
\hline Open-globe ${ }^{\mathrm{a}}, n(\%)$ & $49(79)$ \\
\hline Closed-globe, $n(\%)$ & $12(21)$ \\
\hline Mean follow-up time (range) months & $6(4-34)$ \\
\hline \multicolumn{2}{|l|}{ Primary surgery } \\
\hline Open-globe repair, $n(\%)$ & $31(51)$ \\
\hline Evisceration/enucleation, $n(\%)$ & $17(28)$ \\
\hline Globe exploration, $n(\%)$ & $3(5)$ \\
\hline PPV for retinal detachment ${ }^{\mathrm{b}}, n(\%)$ & $3(5)$ \\
\hline No surgery, $n(\%)$ & $7(11)$ \\
\hline
\end{tabular}


Table 2 Classification of the variables according to ocular trauma classification system

\begin{tabular}{|c|c|}
\hline & Number of eyes \\
\hline \multicolumn{2}{|l|}{ Type of injury } \\
\hline \multicolumn{2}{|l|}{ Open-globe } \\
\hline \multicolumn{2}{|l|}{ IOFB } \\
\hline Perforating & 6 \\
\hline Rupture & 4 \\
\hline Penetrating & 2 \\
\hline \multicolumn{2}{|l|}{ Closed-globe } \\
\hline Contusion & 11 \\
\hline Lamellar laceration & 1 \\
\hline \multicolumn{2}{|l|}{ Presenting VA } \\
\hline \multicolumn{2}{|l|}{ Open-globe } \\
\hline$>20 / 40$ & 0 \\
\hline $20 / 50-20 / 100$ & 0 \\
\hline $19 / 200-5 / 200$ & 2 \\
\hline 4/200-LP & 25 \\
\hline NLP & 22 \\
\hline \multicolumn{2}{|l|}{ Closed-globe } \\
\hline$>20 / 40$ & 1 \\
\hline $20 / 50-20 / 100$ & 4 \\
\hline $19 / 200-5 / 200$ & 5 \\
\hline 4/200-LP & 2 \\
\hline NLP & 0 \\
\hline \multicolumn{2}{|l|}{ Zone } \\
\hline \multicolumn{2}{|l|}{ Open-globe } \\
\hline I (cornea) & 13 \\
\hline II (Limbus to $5 \mathrm{~mm}$ into sclera) & 4 \\
\hline III (Posterior sclera) & 32 \\
\hline \multicolumn{2}{|l|}{ Closed-globe } \\
\hline I (Corneal/conjunctival surface) & 0 \\
\hline II (Anterior segment including pars plicata) & 5 \\
\hline III (Posterior segment) & 7 \\
\hline \multicolumn{2}{|l|}{$R A P D^{\mathrm{a}}$} \\
\hline \multicolumn{2}{|l|}{ Open-globe } \\
\hline Positive & 4 \\
\hline Negative & 9 \\
\hline \multicolumn{2}{|l|}{ Closed-globe } \\
\hline Positive & 5 \\
\hline Negative & 7 \\
\hline
\end{tabular}

Abbreviations: IOFB, intraocular foreign body; RAPD, relative afferent pupillary defect; VA visual acuity.

${ }^{a}$ RAPD was documented in 25 eyes.

Classification of the ocular variables according to the Ocular Trauma Group guidelines is presented in Table 2. In 49 eyes with open-globe injury, intraocular foreign body (IOFB) injury was the most frequently encountered type of injury in $37(76 \%)$ eyes, followed by perforating injury in 6 eyes (12\%), globe rupture in 4 eyes $(8 \%)$, and penetrating injury in 2 eyes (4\%). In 12 eyes with closed-
Table 3 Distribution of the concomitant injuries ${ }^{\mathrm{a}}$

\begin{tabular}{lc}
\hline & Number of injuries \\
\hline Maxillofacial injury & 8 \\
Brain injury & 5 \\
Fingertip injuries & 5 \\
Upper/lower-limb fractures & 5 \\
Tympanic membrane perforation & 4 \\
Upper/lower-limb amputations & 4 \\
Thoracic injury & 3 \\
Abdominal injury & 2 \\
Pelvic injury & 1 \\
Neck vascular injury & 1 \\
Facial paralysis & 1
\end{tabular}

${ }^{\text {aS }}$ ome patients had more than one injury.

globe injury, contusion was observed in 11 (92\%) eyes; only one eye showed lamellar laceration. Among eyes with open-globe injuries, 32 (65\%) eyes had zone III injuries, 13 (27\%) had zone I, and $4(8 \%)$ had zone II injuries. Among eyes with closed-globe injuries, seven eyes (58\%) had zone III injuries and five eyes $(42 \%)$ had zone II injuries. The presence or absence of an RAPD was documented in $25(41 \%)$ of the 61 eyes (positive in 9 eyes and negative in 16). For the remaining 36 (59\%) eyes, data on RAPD were not available. In most of the cases, an RAPD could not be documented because of the bilateral globe damage.

Of the 39 patients with ocular injuries, 27 (69\%) had concomitant serious non-ocular injuries. The data for three patients with traumatic brain injury who died before completion of ocular surgery were not included in the study. The distribution of these injuries is listed in Table 3 .

\section{Primary surgical interventions}

The repair of corneal/corneoscleral laceration or defect was required in $31(51 \%)$ eyes. In 17 (28\%) eyes with globes completely disrupted by IEDs, evisceration or enucleation was performed as a primary surgical procedure (in two cases, evisceration was performed bilaterally). Pars plana vitrectomy was performed as a primary surgery in three eyes in which retinal detachment and vitreous haemorrhage were diagnosed (one eye also had an IOFB). Of these eyes, two required additional vitreoretinal surgery for recurrent retinal detachment due to proliferative vitreoretinopathy (PVR). In three eyes presented with closed-globe injury, surgical exploration was performed to exclude a possible scleral laceration. In these eyes, corneal and conjunctival foreign bodies were also removed during exploration; lamellar scleral laceration was observed in only one of these eyes. 
Table 4 Distribution of the secondary surgical interventions

\begin{tabular}{|c|c|}
\hline & Number of eyes \\
\hline PPV for retinal detachment and IOFB removal & 10 \\
\hline PPV for IOFB removal & 8 \\
\hline Lid/socket/symblepharon surgery & 8 \\
\hline Anterior segment surgery alone $\mathrm{a}^{\mathrm{a}}$ & 6 \\
\hline PPV for retinal detachment ${ }^{b}$ & 4 \\
\hline Evisceration & 2 \\
\hline PPV for dense vitreous haemorrhage & 1 \\
\hline \multicolumn{2}{|c|}{$\begin{array}{l}\text { Abbreviations: PPV, pars plana vitrectomy; IOFB, intraocular foreign } \\
\text { body. } \\
\text { aAnterior segment surgery including lensectomy, intraocular lens } \\
\text { implantation, pupilloplasty, or removal of foreign body from anterior } \\
\text { segment. } \\
\text { bTwo eyes underwent PPV for recurrent retinal detachment due to } \\
\text { proliferative vitreoretinopathy. }\end{array}$} \\
\hline
\end{tabular}

\section{Secondary surgical interventions}

After primary surgical intervention, 39 (64\%) eyes underwent secondary surgical procedures. Vitreoretinal surgical interventions were performed in 23 eyes. Pars plana vitrectomy was performed for retinal detachment repair in 10 eyes with IOFB. In four eyes without IOFB, PPV was performed for retinal detachment repair; two of these eyes had also received primary PPV for retinal detachment and vitreous haemorrhage. Although eight eyes without retinal detachment underwent PPV for removal of IOFB, one eye underwent PPV for dense vitreous haemorrhage. Anterior segment surgery, including lens extraction, intraocular lens implantation, or pupilloplasty with anterior vitrectomy was performed in six eyes (IOFB was also removed from the anterior segment in two of these eyes). Evisceration was required in two eyes that rapidly developed phthisis after the repair of ruptured globes. Oculoplastic surgical procedures including symblepharon repair and eyelid or socket surgery were performed in eight eyes. None of the eyes (including eviscerated or enucleated eyes) had clinical signs of endophthalmitis associated with ocular injuries. The distribution of the secondary surgical interventions is summarised in Table 4.

\section{Details of vitreoretinal surgical procedures}

Vitreoretinal surgical procedures were performed in 24 eyes from 20 patients; of these eyes, three underwent PPV as a primary surgical procedure. Out of 24 eyes, 22 (92\%) that underwent PPV had open-globe injuries; only two had closed-globe injuries. The mean time for vitreoretinal surgical intervention for posterior segment reconstruction after initial injury was $14 \pm 9$ days (range, 4-31 days). The waiting period for vitreoretinal surgery was more than 14 days in patients with life-threatening conditions. The delay in the vitreoretinal surgical intervention (later than 14 days) was not found to be associated with poor visual outcome (Fisher's exact test, $P=0.635)$. The details of vitreoretinal surgical interventions, ocular features, initial and final visual acuity levels, PVR, and the presence or absence of phthisis bulbi are shown in Table 5. When excluding 17 eyes with traumatic evisceration and 2 eyes that subsequently developed phthisis before vitreoretinal surgery, retinal detachment was observed in 15 (63\%) eyes. In $11(73 \%)$ of these 15 eyes, vitreoretinal surgery for retinal detachment was combined with IOFB removal. In four eyes of those with severe corneal injury obscuring the operative view, vitreoretinal surgical procedures could be performed using temporary keratoprosthesis in combination with autokeratoplasty. Open-sky vitrectomy and penetrating keratoplasty were performed in one eye that subsequently became hypotonic with severe corneal thickening following primary open-globe repair. The chorioretinectomy procedure was required in two eyes with IOFB penetrating into the choroid and in one eye with perforating globe injury. All of the three eyes that received chorioretinectomy also displayed retinal detachment.

Postoperative PVR was observed in $12(50 \%)$ of the 24 eyes that underwent vitreoretinal surgery for any reason. All of the eyes that developed postoperative PVR had retinal detachment, and nine of the eyes also had an IOFB. Of these 12 eyes with PVR, 4 eyes subsequently became phthisical. In four of the eyes, retinal reattachment was achieved with additional vitreoretinal surgical interventions, including extensive membrane peeling and retinectomy. In the remaining four eyes, retinal redetachment occurred due to severe PVR. All of the eyes that required chorioretinectomy had postoperative PVR, but none of the eyes developed phthisis bulbi. No postoperative vitreoretinal complication requiring additional vitreoretinal surgery was noted in any of the eyes that underwent PPV for IOFB removal or in the one eye treated with PPV for dense vitreous haemorrhage.

In all of the eyes with retinal detachment, silicone oil was used for internal tamponade; six eyes were filled with heavy silicone, five eyes with $1000 \mathrm{cs}$, and four eyes with 5000 cs silicone oil during the first PPV. Silicone oil removal was performed at least 4 months after surgery. Silicone oil was left as a permanent tamponade in two eyes with severe PVR.

\section{Anatomical and visual outcomes}

Evisceration or enucleation procedures were performed in $19(31 \%)$ of the 61 eyes. Of the 39 patients, 3 of the 39 cases underwent bilateral evisceration (this procedure 
Table 5 Details of the vitreoretinal surgical interventions

\begin{tabular}{|c|c|c|c|c|c|c|c|c|c|}
\hline Patient & $\begin{array}{l}\text { Age } \\
\text { (in } \\
\text { years) }\end{array}$ & Eye & $\begin{array}{l}\text { Open-globe } \\
\text { injuryl } \\
\text { primary OGR }\end{array}$ & $\begin{array}{l}\text { Posterior segment } \\
\text { findings }\end{array}$ & Vitreoretinal surgical intervention & $\begin{array}{l}\text { Initial } \\
\text { VA level }\end{array}$ & $\begin{array}{l}\text { Final } \\
\text { VA level }\end{array}$ & $P V R$ & Phthisis \\
\hline 1 & 26 & Left & Yes/yes & $\mathrm{IOFB}+\mathrm{IVH}$ & Standard 20-G PPV, IOFB removal & 4/200-LP & 4/200-LP & No & No \\
\hline 2 & 28 & Left & Yes/yes & $\mathrm{IOFB}+\mathrm{IVH}$ & Standard 20-G PPV, IOFB removal & 4/200-LP & 4/200-LP & No & No \\
\hline 3 & 20 & Left & Yes/yes & $\mathrm{RD}+\mathrm{IOFB}+\mathrm{IVH}$ & $\begin{array}{l}\text { 20-G PPV with TKP, IOFB removal, } \\
\text { AK, HSiO }\end{array}$ & 4/200-LP & 4/200-LP & Yes & No \\
\hline 4 & 20 & Left & Yes/yes & $\mathrm{RD}+\mathrm{IOFB}+\mathrm{IVH}$ & $\begin{array}{l}\text { Standard 20-G PPV, IOFB removal, } \\
\text { chorioretinectomy, } 5000 \mathrm{cs} \mathrm{SiO}\end{array}$ & 4/200-LP & NLP & Yes & No \\
\hline 5 & 21 & Left & Yes/yes & $\mathrm{RD}+\mathrm{IOFB}+\mathrm{IVH}$ & $\begin{array}{l}\text { Standard 20-G PPV, IOFB removal, } \\
5000 \mathrm{cs} \mathrm{SiO}\end{array}$ & 4/200-LP & 4/200-LP & Yes & Yes \\
\hline \multirow[t]{2}{*}{6} & \multirow[t]{2}{*}{20} & Right & Yes/yes & $\mathrm{IOFB}+\mathrm{IVH}$ & Standard 20-G PPV, IOFB removal & $19 / 100-5 / 200$ & $>20 / 40$ & No & No \\
\hline & & Left & Yes/yes & $\mathrm{IOFB}+\mathrm{IVH}$ & Standard 20-G PPV, IOFB removal & 4/200-LP & 4/200-LP & No & No \\
\hline \multirow[t]{2}{*}{7} & \multirow[t]{2}{*}{21} & Right & Yes/yes & $\mathrm{RD}+\mathrm{IOFB}+\mathrm{IVH}$ & $\begin{array}{l}\text { 20-G PPV with TKP, IOFB removal, } \\
\text { AK, HSiO }\end{array}$ & NLP & NLP & Yes & Yes \\
\hline & & Left & Yes/yes & $\mathrm{RD}+\mathrm{IOFB}+\mathrm{IVH}$ & $\begin{array}{l}\text { Standard 20-G PPV, IOFB removal, } \\
\text { chorioretinectomy, } 1000 \mathrm{cs} \mathrm{SiO}\end{array}$ & 4/200-LP & 4/200-LP & Yes & No \\
\hline \multirow[t]{2}{*}{8} & \multirow[t]{2}{*}{20} & Right & Yes $/$ no $^{\mathrm{a}}$ & $\mathrm{RD}+\mathrm{IOFB}+\mathrm{IVH}$ & $\begin{array}{l}\text { Standard 20-G PPV, IOFB removal, } \\
1000 \mathrm{cs} \mathrm{SiO}\end{array}$ & 4/200-LP & $20 / 50-20 / 100$ & No & No \\
\hline & & Left & Yes/yes & $\mathrm{RD}+\mathrm{IOFB}+\mathrm{IVH}$ & $\begin{array}{l}\text { 20-G PPV with TKP, IOFB removal, } \\
\text { AK, } 1000 \text { cs } \mathrm{SiO}\end{array}$ & 4/200-LP & NLP & Yes & No \\
\hline 9 & 20 & Right & No & $\mathrm{RD}+\mathrm{IVH}$ & Standard 20-G PPV, HSiO & 4/200-LP & NLP & Yes & No \\
\hline 10 & 25 & Left & Yes/yes & $\mathrm{RD}+\mathrm{IOFB}+\mathrm{IVH}$ & $\begin{array}{l}\text { Standard 20-G PPV, IOFB removal, } \\
\text { HSiO }\end{array}$ & NLP & NLP & Yes & No \\
\hline 11 & 35 & Right & Yes/yes & $\mathrm{RD}$ & Standard $20-\mathrm{G}$ PPV, $1000 \mathrm{cs} \mathrm{SiO}$ & 4/200-LP & $>20 / 40$ & No & No \\
\hline \multirow[t]{2}{*}{12} & \multirow[t]{2}{*}{34} & Right & Yes/yes & $\mathrm{RD}+\mathrm{IOFB}+\mathrm{IVH}$ & $\begin{array}{l}\text { Standard 20-G PPV, IOFB removal, } \\
1000 \mathrm{cs} \mathrm{SiO}\end{array}$ & 4/200-LP & $20 / 50-20 / 100$ & No & No \\
\hline & & Left & Yes/yes & $\mathrm{RD}+\mathrm{IOFB}+\mathrm{IVH}$ & $\begin{array}{l}\text { 20-G PPV with TKP, IOFB removal, } \\
\text { AK, HSiO }\end{array}$ & 4/200-LP & 4/200-LP & Yes & Yes \\
\hline 13 & 21 & Left & Yes/yes & $\mathrm{IOFB}+\mathrm{IVH}$ & Standard 20-G PPV, IOFB removal & 4/200-LP & $20 / 50-20 / 100$ & No & No \\
\hline 14 & 42 & Right & No & $\mathrm{RD}+\mathrm{IVH}$ & Standard 20-G PPV, HSiO & $19 / 100-5 / 200$ & 4/200-LP & Yes & No \\
\hline 15 & 30 & Left & Yes/yes & $\mathrm{IOFB}+\mathrm{IVH}$ & Standard 20-G PPV, IOFB removal & 4/200-LP & $20 / 50-20 / 100$ & No & No \\
\hline 16 & 20 & Left & Yes/yes & $\mathrm{RD}+\mathrm{IVH}$ & $\begin{array}{l}\text { Standard 20-G PPV, chorioretinectomy, } \\
5000 \mathrm{cs} \mathrm{SiO}\end{array}$ & 4/200-LP & 4/200-LP & Yes & No \\
\hline 17 & 26 & Left & Yes/yes & $\mathrm{RD}+\mathrm{IOFB}+\mathrm{IVH}$ & $\begin{array}{l}\text { Open-sky vitrectomy, IOFB removal, } \\
\text { PK, } 5000 \mathrm{cs} \mathrm{SiO}\end{array}$ & 4/200-LP & 4/200-LP & Yes & Yes \\
\hline 18 & 23 & Left & Yes/yes & $\mathrm{IOFB}+\mathrm{IVH}$ & Standard 20-G PPV, IOFB removal & 4/200-LP & $19 / 100-5 / 200$ & No & No \\
\hline 19 & 21 & Right & Yes/yes & IVH & Standard 20-G PPV & 4/200-LP & $19 / 100-5 / 200$ & No & No \\
\hline 20 & 21 & Left & Yes/yes & $\mathrm{IOFB}+\mathrm{IVH}$ & Standard 20-G PPV, IOFB removal & 4/200-LP & $>20 / 40$ & No & No \\
\hline
\end{tabular}

Abbreviations: AK, autokeratoplasty; HSiO, heavy silicone oil; IOFB, intraocular foreign body; IVH, intravitreal haemorrhage; LP, light perception; NLP, no light perception; OGR, open-globe repair; PK, penetrating keratoplasty; PPV, pars plana vitrectomy; PVR, proliferative vitreoretinopathy; $\mathrm{RD}$, retinal detachment, $\mathrm{SiO}$, silicone oil; VA, visual acuity; TKP, temporary keratoprosthesis.

${ }^{\mathrm{a} O p e n-g l o b e ~ i n j u r y ~ n o t ~ r e q u i r i n g ~ p r i m a r y ~ g l o b e ~ r e p a i r . ~}$

was performed as a primary surgical intervention in two cases), and 8 patients (21\%) had no light perception in either eye. Phthisis bulbi developed in two eyes operated upon with temporary keratoprostheses and in one eye that underwent open-sky vitrectomy. In addition, one eye became phthisical because of recurrent retinal detachment with severe PVR. In two eyes that required recurrent vitreoretinal surgical interventions for PVR, silicone oil was left as a permanent internal tamponade because of the risk of subsequent hypotony and phthisis. In two eyes without vitreoretinal surgery, phthisis developed immediately after open-globe repair.

The presenting and final visual acuity levels are listed in Table 6. Twelve (20\%) eyes had 5/200 or better visual acuity at presentation and $22(36 \%)$ eyes had no light
Table 6 Presenting and final visual acuity levels in open/ closed-globe injuries

\begin{tabular}{lccccc}
\hline Presenting VA levels & \multicolumn{5}{c}{ Final VA levels } \\
\cline { 2 - 6 } & $>20 / 40$ & $\begin{array}{c}20 / 50- \\
20 / 100\end{array}$ & $5 / 200-$ & $4 / 200-L P$ & $N L P$ \\
& \multicolumn{5}{c}{$5 / 200$} \\
\hline Open-globe & 2 & 0 & 0 & 0 & 0 \\
$19 / 200-5 / 200$ & 2 & 6 & 4 & 10 & 3 \\
$4 / 200-L P$ & 0 & 0 & 0 & 0 & 22 \\
NLP & & & & & \\
Closed-globe & 1 & 0 & 0 & 0 & 0 \\
$>20 / 40$ & 3 & 0 & 0 & 1 & 0 \\
$20 / 50-20 / 100$ & 4 & 0 & 0 & 1 & 0 \\
$19 / 200-5 / 200$ & 0 & 1 & 0 & 0 & 1 \\
$4 / 200-L P$ & & & & \\
\hline
\end{tabular}

Abbreviations: LP, light perception; NLP, no light perception; VA visual acuity. 
perception. At the last follow-up, visual acuity of 5/200 or better was achieved in 23 (38\%) eyes; 19 of them (31\%) had visual acuity of 20/100 or better. Twenty-six (43\%) eyes had no light perception.

\section{Prognostic factors}

Statistical analysis demonstrated that presenting visual acuity worse than 5/200 was significantly associated with poor visual outcome (McNemar's test, $P=0.007$ ). Open-globe injuries were significantly associated with poor visual outcome when compared with closed-globe injuries (Fisher's exact test, $P=0.006$ ). The presence of an RAPD at initial examination was found to be statistically associated with poor visual outcome in 25 eyes in which an RAPD had been documented (Fisher's exact test, $P=0.01$ ). In eyes diagnosed with open-globe injury, the presence of an IOFB was not associated with poor visual outcome (Fisher's exact test, $P=0.076$ ). Concomitant non-ocular injuries were not found to be associated with poor visual outcome ( $\chi^{2}$-test, $\left.P=0.698\right)$.

\section{Discussion}

Improvised explosive devices are increasingly being used by insurgents or terrorist groups worldwide and are responsible for $38 \%$ of all combat injuries and $32 \%$ of combat fatalities. ${ }^{7-9}$ These are also primarily responsible for severe ocular and ocular adnexal injuries, and have become a major source of ocular morbidity. ${ }^{3}$ The detrimental effects of these explosive devices placed adjacent to the convoy route have been exacerbated through the use of secondary projectiles such as rocks, metal, or glass pieces. These explosive mechanisms are being activated by radio frequency remote control. In contrast to landmines, IEDs are typically placed at a substantial height from the ground (at the height of the vehicle) so as to cause fatal injury. Therefore, injuries from IEDs are strongly associated with head injuries and bilateral ocular involvement requiring extensive surgical repair and debridement. Another prominent feature of the associated ocular trauma is that ocular structural damage caused by IEDs is strongly correlated with poor globe salvage. In the current study, 17 (28\%) eyes with severe globe damage from IEDs underwent evisceration or enucleation immediately after trauma. Unfortunately, this procedure was required bilaterally in 3 of the 39 patients.

In cases with extreme ocular trauma resulting from explosives, there may be a need for extensive surgical interventions such as enlargement of sclerotomy sites for removal of large IOFBs, and retinectomy or chorioretinectomy for management of posterior segment complications. In this type of injury, standard 20-gauge
PPV represents a safe and effective surgical approach. In a study by Weichel et al, ${ }^{10}$ the chorioretinectomy procedure was reported to be effective in achieving better anatomical and visual outcomes in perforating or severe IOFB injuries. This surgical technique was described as a proactive approach for use in perforating eye injuries that results in a significant reduction in the incidence of PVR. ${ }^{11}$ Theoretically, PPV combined with chorioretinectomy seems to be an effective approach in the management of posterior segment reconstruction with regard to the removal of factors associated with PVR. In our study, the chorioretinectomy procedure was performed in two eyes with IOFB injury and in one eye with globe perforation, but postoperative PVR developed in all three eyes. Although it is difficult to define predisposing factors related to PVR, this may be associated with the time to surgical intervention as well as the nature of the explosive materials used in terrorist acts. In the current study, the time interval from injury to vitreoretinal surgical intervention averaged 14 days with the standard deviation of 9 days. The high value of standard deviation was mainly because of the long recovery time for life-threatening events in some cases. The timing of surgery was determined by whether the globe integrity and corneal transparency was restored. The time to vitreoretinal surgery was longer in critically injured patients who received intensive care.

Proliferative vitreoretinopathy following ocular trauma is a potential serious complication leading to poor visual outcome and may require extensive vitreoretinal surgical interventions, depending on the nature of the trauma. ${ }^{12}$ In a series of combat ocular trauma cases with perforating or severe IOFB injuries, postoperative PVR was reported in $69 \%$ of the eyes. ${ }^{10}$ In the current study, postoperative PVR developed in $12(50 \%)$ of the 24 eyes that underwent vitreoretinal surgery for any reason. All of the 12 eyes with PVR had retinal detachment; of these eyes, 9 eyes also had at least one IOFB and coexisting vitreous haemorrhage.

Ocular injuries from explosive devices are mostly associated with multiple embedded corneal fragments and partial and/or full-thickness irregular corneal lacerations requiring extensive suturing and debridement. In such cases, the use of temporary keratoprosthesis allows a clear operative view during vitreoretinal surgery and may provide the possibility of earlier posterior segment reconstruction. This procedure has been described as a combination of temporary keratoprosthesis, PPV, and penetrating keratoplasty. ${ }^{13-17}$ In severely injured eyes, corneal graft failure and phthisis bulbi are known to be common postoperative complications, especially in cases in which silicone oil has been used. ${ }^{14,15,17}$ In our study, the surgical procedure was combined with autokeratoplasty because of the 
increased risk of graft failure or lack of available corneal graft in four eyes that underwent vitreoretinal surgery using temporary keratoprosthesis; therefore, we cannot draw a definite conclusion regarding the survival of corneal grafts. However, in one eye that underwent open-sky vitrectomy with penetrating keratoplasty, the corneal graft rapidly became completely opaque, and the eye became phthisical.

Although the mean follow-up period of 6 months (range, 4-34 months) was relatively short, development of sympathetic ophthalmia was not observed in the current series. We also did not observe any case of endophthalmitis associated with open-globe injury. In a previous study reported by our department, endophthalmitis following open-globe injuries was reported in $9 \%$ of the 199 eyes. ${ }^{18}$ Although most of the injuries resulted from dirty materials such as rocks, stones, and metals covered with soil, the absence of any case of endophthalmitis was remarkable. In addition, with the exception of intravenous or oral antibiotic therapy, no patient received intraocular antibiotics preoperatively or at the time of surgery. However, a previous series reported no cases of endophthalmitis following ocular trauma due to explosive material. ${ }^{19-22}$ In most of the patients, signs of burns on the eyelids and ocular surface and in the vitreous gel suggested that injuries from hot, projectile particles may be associated with endophthalmitis less frequently than are other penetrating ocular injuries.

Ocular injuries due to IEDs are typically associated with life-threatening systemic injuries. In a large series of patients with combat ocular trauma, traumatic brain injury was reported as the most common associated injury, observed in $66 \%$ of patients. ${ }^{5}$ In our study, five patients experienced concomitant traumatic brain injury. In addition, three patients with ocular injury expired because of severe head trauma before the completion of ocular surgical interventions. Sixty-nine percent of patients included in the study had concomitant nonocular injuries. Orthopaedic injuries and maxillofacial injuries were the most frequently encountered concomitant injuries. Four patients presented with traumatic amputation of the upper or lower limb.

In the current study, presenting visual acuity worse than $5 / 200$ was significantly associated with poor visual outcome $(P<0.05)$. Open-globe injuries were also significantly associated with poor visual outcome when compared with closed-globe injuries $(P<0.05)$. The presence of an RAPD in the affected eye has been reported as predictive of good visual outcome in the context of combat-related ocular injuries. ${ }^{5}$ In our study, the presence or absence of an RAPD was not documented because of the bilateral ocular involvement. However, in eyes in which pupillary examination had been documented, the presence of an RAPD was found to be associated with poor visual outcome $(P<0.05)$.

In conclusion, ocular injuries due to IEDs are strongly associated with severe globe damage. Because of the extremely destructive nature of the IEDs, evisceration or enucleation procedures may be the only treatment option available in the management of these types of injuries.

Postoperative PVR is a common cause of poor anatomical and visual outcome.

\section{Summary}

\section{What was known before}

- Ocular injuries caused by explosive materials are strongly associated with severe ocular morbidity and visual impairment.

\section{What this study adds}

- In terrorist acts, improvised explosive devices have been used increasingly in recent years. In this study, we aimed to present the devastating ocular injuries caused by these types of explosive devices.

\section{Conflict of interest}

The authors declare no conflict of interest.

\section{References}

1 Bajaire B, Oudovitchenko E, Morales E. Vitreoretinal surgery of the posterior segment for explosive trauma in terrorist warfare. Graefes Arch Clin Exp Ophthalmol 2006; 244: 991-995.

2 Colyer MH, Chun DW, Bower KS, Dick JS, Weichel ED. Perforating globe injuries during operation Iraqi Freedom. Ophthalmology 2008; 115: 2087-2093.

3 Mader TH, Carroll RD, Slade CS, George RK, Ritchey JP, Neville SP. Ocular war injuries of the Iraqi insurgency, January-September 2004. Ophthalmology 2006; 113: 97-104.

4 Sobaci G, Akyn T, Mutlu FM, Karagul S, Bayraktar MZ. Terror-related open-globe injuries: a 10-year review. Am J Ophthalmol 2005; 139: 937-939.

5 Weichel ED, Colyer MH, Ludlow SE, Bower KS, Eiseman AS. Combat ocular trauma visual outcomes during operations Iraqi and Enduring Freedom. Ophthalmology 2008; 115: 2235-2245.

6 Pieramici DJ, Sternberg Jr P, Aaberg Sr TM, Bridges Jr WZ, Capone Jr A, Cardillo JA et al. A system for classifying mechanical injuries of the eye (globe). The Ocular Trauma Classification Group. Am J Ophthalmol 1997; 123: 820-831.

7 Holcomb JB, McMullin NR, Pearse L, Caruso J, Wade CE, Oetjen-Gerdes L et al. Causes of death in U.S. Special Operations Forces in the global war on terrorism: 2001-2004. Ann Surg 2007; 245: 986-991.

8 Owens BD, Kragh Jr JF, Wenke JC, Macaitis J, Wade CE, Holcomb JB. Combat wounds in operation Iraqi Freedom and operation Enduring Freedom. J Trauma 2008; 64: 295-299. 
9 Ramasamy A, Harrisson SE, Clasper JC, Stewart MP. Injuries from roadside improvised explosive devices. J Trauma 2008; 65: 910-914.

10 Weichel ED, Bower KS, Colyer MH. Chorioretinectomy for perforating or severe intraocular foreign body injuries. Graefes Arch Clin Exp Ophthalmol 2010; 248: 319-330.

11 Kuhn F, Mester V, Morris R. A proactive treatment approach for eyes with perforating injury. Klin Monbl Augenheilkd 2004; 221: 622-628.

12 Cardillo JA, Stout JT, LaBree L, Azen SP, Omphroy L, Cui JZ et al. Post-traumatic proliferative vitreoretinopathy. The epidemiologic profile, onset, risk factors, and visual outcome. Ophthalmology 1997; 104: 1166-1173.

13 Eckardt C. A new temporary keratoprosthesis for pars plana vitrectomy. Retina 1987; 7: 34-37.

14 Gallemore RP, Bokosky JE. Penetrating keratoplasty with vitreoretinal surgery using the Eckardt temporary keratoprosthesis: modified technique allowing use of larger corneal grafts. Cornea 1995; 14: 33-38.

15 Gelender H, Vaiser A, Snyder WB, Fuller DG, Hutton WL. Temporary keratoprosthesis for combined penetrating keratoplasty, pars plana vitrectomy, and repair of retinal detachment. Ophthalmology 1988; 95: 897-901.

16 Landers 3rd MB, Foulks GN, Landers DM, Hickingbotham D, Hamilton RC. Temporary keratoprosthesis for use during pars plana vitrectomy. Am J Ophthalmol 1981; 91: 615-619.

17 Roters S, Szurman P, Hermes S, Thumann G, Bartz-Schmidt $\mathrm{KU}$, Kirchhof B. Outcome of combined penetrating keratoplasty with vitreoretinal surgery for management of severe ocular injuries. Retina 2003; 23: 48-56.

18 Sabaci G, Bayer A, Mutlu FM, Karagul S, Yildirim E. Endophthalmitis after deadly-weapon-related open-globe injuries: risk factors, value of prophylactic antibiotics, and visual outcomes. Am J Ophthalmol 2002; 133: 62-69.

19 Blanch RJ, Bindra MS, Jacks AS, Scott RA. Ophthalmic injuries in British Armed Forces in Iraq and Afghanistan. Eye (Lond) 2011; 25: 218-223.

20 Colyer MH, Weber ED, Weichel ED, Dick JS, Bower KS, Ward TP et al. Delayed intraocular foreign body removal without endophthalmitis during Operations Iraqi Freedom and Enduring Freedom. Ophthalmology 2007; 114: 1439-1447.

21 Thach AB, Ward TP, Dick 2nd JS, Bauman WC, Madigan Jr WP, Goff MJ et al. Intraocular foreign body injuries during Operation Iraqi Freedom. Ophthalmology 2005; 112: 1829-1833.

22 Weichel ED, Colyer MH. Combat ocular trauma and systemic injury. Curr Opin Ophthalmol 2008; 19: 519-525. 